\title{
La prueba como elemento esencial del debido procedimiento administrativo
}

\section{Evidence as an essential element of administrative due procedure}

\author{
Maite Aguirrezabal Grünstein \\ Juan Carlos Flores Rivas"
}

El presente trabajo aborda aspectos vinculados al contenido del derecho a la prueba como un elemento esencial del debido procedimiento racional y justo en sede administrativa con la finalidad de establecer algunos parámetros para su proposición, admisión y valoración. Se busca determinar, si la ausencia de prueba en el procedimiento administrativo, atenta contra la garantía del debido proceso, particularmente en los procedimientos contenciosos especiales, cuya regulación
This work addresses aspects related to the content of the right to due procedure and evidence in administrative headquarters in order to establish some parameters for its proposal, admission and evaluation. It seeks to determine whether the absence of evidence in the administrative procedure, particularly in special contentious procedures, threatens the guarantee of due process, since the courts limit themselves to confirming the administrative decision without

\footnotetext{
* Profesora Investigadora de la Facultad de Derecho de la Universidad de los Andes. Doctora en Derecho por la Universidad de Navarra, Magíster en Derecho de la Empresa por la Universidad de los Andes y Diplomada en suficiencia investigadora por la Universidad de Nava. Correo electrónico: maguirrezabal@uandes.cl. Dirección postal: Monseñor Álvaro del Portillo 12455, Santiago, Las Condes, Región Metropolitana, Chile. El presente trabajo se hace en el marco del proyecto Fondecyt número 1200188, titulado "Revisión crítica de los recursos de reclamación previstos en las leyes orgánicas de las superintendencias vinculadas a mercados regulados. Una propuesta de sistematización a la luz del derecho a la tutela judicial efectiva", del que la autora es Investigadora Responsable.

** Profesor Investigador de la Facultad de Derecho de la Universidad de los Andes. Doctor en Derecho por la Universidad de los Andes y Magíster en Derecho Público por la misma Universidad. Correo electrónico: jcflores@uandes.cl. Dirección postal: Monseñor Álvaro del Portillo 12455, Santiago, Las Condes, Región Metropolitana, Chile. El presente trabajo se hace en el marco del proyecto Fondecyt número 1200188, titulado "Revisión crítica de los recursos de reclamación previstos en las leyes orgánicas de las superintendencias vinculadas a mercados regulados. Una propuesta de sistematización a la luz del derecho a la tutela judicial efectiva", del que el autor es Coinvestigador.
}

Artículo recibido el 14 de abril de 2021 y aceptado el 15 de junio de 2021. 
no prevé el derecho a prueba limitando a los tribunales a confirma la decisión administrativa sin revisar los supuestos fácticos que le han servido de sustento.

Palabras claves: Contencioso administrativo, prueba, debido proceso. reviewing the factual assumptions that have served as support.

Keywords: Administrative dispute, evidence, due process of law.

\section{Introducción}

La prueba, el procedimiento para rendirla y su valoración es uno de los puntos más sensibles dentro del proceso en general y del procedimiento administrativo en particular, puesto que el derecho a la prueba constituye un elemento esencial del debido, racional y justo procedimiento, independientemente de la naturaleza especial o general de dicho procedimiento, debido a que mediante una adecuada acreditación de los supuestos fácticos en los que se funda el ejercicio de un potestad pública, v.gr., fiscalizadoras o sancionatorias, tanto la Administración como el interesado obtienen la ventaja de un acto administrativo fundamentado racionalmente y que busca la satisfacción del interés público sobre la base de hechos debidamente probados.

El presente trabajo se centra en demostrar que la Administración debe garantizar el derecho a la prueba y abrir un término probatorio no solamente en los supuestos de procedimientos sancionadores, sino que en todos aquellos procedimientos donde los hechos no le consten y sea necesario el aporte de antecedentes por parte del administrado. El criterio propuesto resulta especialmente relevante en los procedimientos contenciosos especiales de reclamación, en que generalmente no se ha previsto la posibilidad de rendir prueba con posterioridad, dejando con ello al administrado en una posición de indefensión frente al órgano administrativo, que goza de prueba documental preconstituida mediante actas de inspección.

\section{Consagración constitucional y legal del debido proceso administrativo}

\section{Generalidades}

La justicia administrativa se compone de un conjunto amplio de instrumentos jurídicos para la defensa de los administrados, dentro de los que se incluyen la existencia de una jurisdicción especializada y ejercida por los tribunales, y en sede administrativa y por los entes y órganos de la administración pública1.

De esta manera, la jurisdicción y los procedimientos administrativos se han convertido en mecanismos efectivos, así como en una fuente fundamental de la justicia administrativa, sin desconocer que "la esencia del procedimiento administrativo en general es la de asegurar el cumplimiento posible de los

\footnotetext{
FIX 2005, 166 y ss.
} 
fines de la Administración con respeto a los derechos subjetivos y a los intereses legítimos del administrado, de acuerdo con el ordenamiento jurídico"2.

Nuestro Tribunal Constitucional ha precisado que el debido proceso como "el procedimiento legal debe ser racional y justo. Racional para configurar un proceso lógico y carente de arbitrariedad. Y justo para orientarlo a un sentido que cautele los derechos fundamentales de los participantes en un proceso" 3 .

En este sentido, el debido proceso otorga al administrado la garantía de que podrá hacer valer sus derechos en el ámbito de la Administración ${ }^{4}$, lo cual se traduce conjuntamente con el derecho a la acción y la legalidad del juzgamiento, en el logro de la tutela judicial efectiva" ${ }^{5}$. En definitiva, tal como señala Cordero Vega, la necesidad de que el particular afectado aduzca sus argumentos y exponga sus razonamientos cuando la decisión aún se encuentra en gestación, ha de buscarse en el principio audi alteram parte o prohibición de resolver inaudita parte ${ }^{6}$.

Las exigencias de un debido proceso también han sido recogidas por la Corte Suprema, específicamente en el ámbito del derecho administrativo sancionador, que tomando como referencia y norma básica supletoria la Ley $N^{\circ} 19.880$, y los principios conclusivo, de contradicción, impugnabilidad, transparencia y publicidad establecidos en los artículos 8, 10, 15 y 16, de dicha norma, ha llegado a la conclusión que el respeto del debido proceso es obligatorio para los órganos del Estado:

máxime si se considera que se está en presencia de un procedimiento sancionatorio que culmina con la imposición de una multa, manifestación del ius puniendi estatal, en cuyo ejercicio el ente administrativo debe regirse estrictamente por el principio de legalidad, respetando el derecho básico de los particulares de conocer y defenderse de las imputaciones que se dirigen en su contra ${ }^{7}$.

Por otra parte, en lo que respecta al derecho de defensa en materia administrativa, se ha considerado no solo como una exigencia del principio de justicia sino también como expresión del principio de eficacia ya que asegura un mejor conocimiento de los hechos y contribuye a mejorar la decisión administrativa garantizando que ella sea más justa. Como señala Oelckers:

la garantía del debido proceso que reconoce el Art. $19 \mathrm{~N}^{\circ} 3$ inc. $5^{\circ}$, en el ámbito administrativo se manifiesta en una doble perspectiva: a) el derecho a defensa que debe ser reconocido como la oportunidad para

\footnotetext{
2 Sobre este tema puede consultarse el artículo de Brewer-Carías 2009.

3 Sentencia TC Rol No 1838 (2011).

4 Rojas 2011, 183-184.

5 Sentencia TC Rol No 1130 (2008).

Cordero 2015, 335.

7 Sentencia CS Rol N Rol N62128-2016.
} 
el administrado de hacer oír sus alegaciones, descargos y pruebas y también b) como el derecho de exigir de la Administración Pública el cumplimiento previo de un conjunto de actos procedimentales que le permitan conocer con precisión los hechos que se imputan y las disposiciones legales aplicables a los mismos ${ }^{8}$.

\section{Contenido de un racional y justo procedimiento}

Como señalamos anteriormente, uno de los aspectos más relevantes del derecho de defensa es aquel que se refiere al principio de contradictoriedad que se traduce en el derecho a ser oído en el procedimiento administrativo, ya que la regla de la bilateralidad se convierte en una condición esencial, que debe proyectarse principalmente en la actividad probatoria. En palabras de Conget, se trata de "un aspecto sensible que repercute en un componente sustancial del justo y racional procedimiento garantizado por el artículo 19 numeral 3 de la Constitución"9.

Poblete, entiende que un justo y racional procedimiento administrativo debería contemplar un mínimo de acciones, tales como que permita desplegar el contradictorio en plenitud arbitrando, conforme con las reglas del debido proceso, la posibilidad de evaluar la recepción de la causa a prueba por el juez; arbitrar la actividad probatoria en un tiempo razonable; asegurar que la actividad probatoria deba ajustarse a los principios de inmediación, bilateralidad, igualdad, publicidad y contradicción; valorar la prueba conforme a las reglas especiales que fije el procedimiento y en su silencio, conforme con las reglas procesales civiles generales ${ }^{10}$.

En el mismo sentido, la jurisprudencia constitucional ha dispuesto que un adecuado contradictorio "garantiza a las partes una intervención en condiciones de igualdad sobre las materias que son objeto de la decisión, lo que asegura, entre otros componentes, que la prueba será examinada y discutida por los antagonistas"11. En este sentido, la bilateralidad constituye un principio formativo del procedimiento administrativo, tal como lo ha declarado nuestro Tribunal Constitucional, cuando señala que "el derecho a un proceso previo, legalmente tramitado, racional y justo, que la Constitución asegura a todas las personas, debe contemplar las siguientes garantías: la bilateralidad de la audiencia"12.

Nuestra legislación ha reconocido normativamente esta orientación. El artículo 17 de la Ley N 19880, que consagra normativamente los derechos

\footnotetext{
8 OelCKers 1999, 272. En contra, Valdivia señala que el fundamento de un debido proceso administrativo proviene de una interpretación errada de parte de la jurisprudencia constitucional sobre el alcance de la due process clause del derecho norteamericano, pensada solo para el debido proceso judicial, y no para el procedimiento administrativo nacional. VALDIVIA 2018, 249.

9 Conget 2015, 96 y ss.

10 Cfr. Poblete 2016, 26 y ss.

11 Sentencia TC Rol No 1718 (2010), en que se refiere al principio de presunción de inocencia.

12 Sentencia TC Rol No 1448 (2010).
} 
de los administrados, destaca la posibilidad de "formular alegaciones y aportar documentos en cualquier fase del procedimiento anterior al trámite de audiencia, que deberán ser tenidos en cuenta por el órgano competente al redactar la propuesta de resolución". Luego, el artículo 41, en lo que respecta al contenido de la resolución final, establece que habiendo cuestiones conexas que deban decidirse deberán ser puestas serán puestas en conocimiento de los interesados, quienes dispondrán de un plazo de quince días para formular las alegaciones que estimen pertinentes y aportar, en su caso, medios de prueba $^{13}$.

La misma idea recoge también el artículo 39, cuando consagra la audiencia pública facultativa, que tiene por objeto llamar a todos los terceros interesados a hacer valer sus derechos e intereses y efectuar las alegaciones antes que la decisión se adopte por parte de la Administración cuando aparezca conveniente según la naturaleza del acto, anunciándose una vez a lo menos en el Diario Oficial o en el periódico de circulación nacional o regional correspondiente. En el mismo sentido, el artículo 53 del mismo cuerpo legal habilita a la Administración del Estado para proceder a la invalidación de los actos administrativos previa audiencia del interesado, requisito que ha sido considerado como esencial por la jurisprudencia de la Corte Suprema, por cuanto constituyen un claro ejemplo del principio de contradicción ${ }^{14}$.

\section{La prueba en el procedimiento administrativo}

\section{Generalidades}

Nos corresponde determinar ahora cómo se canaliza el derecho a la prueba en un debido proceso administrativo y cómo nuestra legislación garantiza un adecuado contradictorio ${ }^{15}$, ya que como señalamos, la consecuencia fundamental del derecho a ser oído es el derecho de los interesados a formular alegaciones, defensas y a presentar pruebas. En efecto, el artículo 10 de la Ley $N^{\circ} 19.880$, que establece el principio de contradicción, precisa en su inciso primero que "los interesados podrán, en cualquier momento del procedimiento, aducir alegaciones y aportar documentos u otros elementos de juicio", agregando que también "podrán alegar defectos de tramitación, especialmente los que supongan paralización, infracción de los plazos señalados o la omisión de trámites que pueden ser subsanados antes de la resolución definitiva del asunto".

\footnotetext{
13 Algunas constituciones más modernas, como la de Colombia de 1991, establece en su artículo 29 consagra que "el debido proceso se aplicará a toda clase de actuaciones judiciales y administrativas", mientras que el art. 238 prescribe que los actos administrativos susceptibles de impugnación judicial, podrán ser suspendidos provisionalmente, según lo regule la ley, por la jurisdicción contencioso-administrativa.

14 Sentencia CS Rol No 1827-2014.

15 Bermúdez 2011, 150. Cordero 2015, 402.
} 
En su inciso final, dispone que, en cualquier caso, "el órgano instructor adoptará las medidas necesarias para lograr el pleno respeto a los principios de contradicción y de igualdad de los interesados en el procedimiento". Por igualdad procesal debemos entender la necesidad de que se verifique un "equilibrio procesal necesario otorgando igualdad de armas al interior de un procedimiento" 16 , lo que se traduce en el derecho del administrado a ofrecer prueba para desvirtuar los antecedentes que el fiscalizador ha logrado reunir durante la investigación administrativa. De no ser así, "se estaría rompiendo con el principio de objetividad que debe respetarse en toda investigación" ${ }^{17}$.

Específicamente, los artículos 35 a 38 de la Ley $N^{\circ} 19.880$ regulan la actividad probatoria que se desarrollará dentro del procedimiento administrativo, reconociendo como fundamento de esta regulación el reconocimiento de la garantía del debido proceso consagrado en nuestra Constitución. Al respecto, el Tribunal Constitucional ha indicado que el legislador:

está obligado a permitir que toda parte o persona interesada en un proceso cuente con medios apropiados de defensa que le permitan oportuna y eficazmente presentar sus pretensiones, discutir las de la otra parte, presentar pruebas e impugnar las que otros presenten, de modo que, si aquéllas tienen fundamento, permitan el reconocimiento de sus derechos, el restablecimiento de los mismos o la satisfacción que, según el caso, proceda; excluyéndose, en cambio, todo procedimiento que no permita a una persona hacer valer sus alegaciones o defensas o las restrinja de tal forma que la coloque en una situación de indefensión o inferioridad ${ }^{18}$.

La prueba en el procedimiento administrativo se encuentra regida también por el principio de imparcialidad, contemplado en el artículo 11 de la ley, y en virtud del cual, la Administración debe actuar con objetividad y respetar el principio de probidad consagrado en la legislación, tanto en la substanciación del procedimiento, lo cual la obliga a motivar en forma suficiente los actos administrativos que limiten, restrinjan, priven, perturben o amenacen el legítimo ejercicio de derechos, así como aquellos que resuelvan recursos administrativos.

\section{Apertura de un periodo de prueba: ¿facultativa u obligatoria?}

Tal como señalamos previamente, la prueba se inserta en el procedimiento como una actuación de instrucción en favor del ciudadano ante la Administración. Claramente, en un procedimiento administrativo la procedencia de la prueba no se ajusta a los parámetros normales de los procedimientos civiles $^{19}$. Al no existir un contradictorio propiamente tal entre partes procesalmente iguales, no es posible hablar sobre la existencia de hechos sustan-

\footnotetext{
16 García 2013, 267.

17 Maturana 2014, 566.

18 Sentencia TC Rol No 1411 (2009).

19 Valdivia 2018, 250.
} 
ciales, pertinentes y controvertidos de la manera como se explica a propósito de un procedimiento civil tradicional, puesto que el órgano administrativo no está llamado a aplicar el derecho para la solución de un conflicto concreto, sino que más a la satisfacción de necesidades de carácter público y el correcto ejercicio de la potestad administrativa.

A primera vista se puede inferir que esta etapa es meramente eventual, ya que de acuerdo con lo dispuesto en el artículo 35 de la Ley $N^{\circ} 19.880$, solo sería necesaria la apertura de un período de prueba, cuando a la Administración no le constan los hechos alegados por los interesados o la naturaleza del procedimiento lo exija. Por lo mismo, sería facultativo para la Administración la decisión sobre si abrir o no un término probatorio, y queda a su discreción evaluar si los hechos alegados por los interesados le constan a la Administración o no.

En atención al principio antes mencionado, se han efectuado alegaciones en el sentido que el artículo 35 presentaría rasgos de inconstitucionalidad, ya que, en ciertos casos, permitiría a la Administración exonerarse de esa obligación de recibir la controversia a prueba y porque la carga de la prueba se trasladaría injustificadamente al administrado, al tener que individualizar los hechos que no le constan a dicha autoridad ${ }^{20}$. El Tribunal Constitucional en la causa Rol N² 2682 de 2014, precisa por ejemplo que las sanciones administrativas deben ser:

precedidas de una formulación de cargos, donde se precisen los hechos imputados, seguida de una oportunidad real para plantear descargos, donde la defensa pueda incluso invocar hechos nuevos o distintos -no considerados por el fiscalizador- con el propósito de desvirtuar esa acusación o, al menos, para fundamentar atenuantes ${ }^{21}$.

Agrega la sentencia que un debido proceso, exige "la formulación de cargos, su notificación al inculpado, seguida de una oportunidad efectiva para que este pueda ejercer el derecho a defensa, incluida la posibilidad de allegar y producir pruebas"22, y que la autoridad administrativa "se encuentra en el imperativo de sustanciar un procedimiento justo y racional que satisfaga las garantías del artículo 19, No3, constitucional".

De esta forma, a la imposición de sanciones administrativas:

necesariamente debe anteceder una serie concatenada de trámites, tan esenciales como un acta o acusación o formulación de cargos precisa

\footnotetext{
20 En este caso en particular, el Tribunal señaló que "la ley orgánica de la Superintendencia de Valores y Seguros, Decreto Ley $N^{\circ} 3538$, de 1980, no establece que esta entidad fiscalizadora tenga la obligación de fijar los hechos sobre los que debe recaer la prueba, después de recibir los descargos de un acusado en que se acompañan antecedentes o se solicita la práctica de diligencias probatorias, agregando que este mismo trato procedimental se encuentra reconocido en otros procedimientos seguidos ante diversas superintendencias.

21 Sentencia TC Rol N² 2682 (2014).

22 ĺdem.
} 
y sostenida en una investigación previa, su comunicación al presunto infractor y la oportunidad para que este pueda plantear defensas o alegaciones y rendir pruebas ${ }^{23}$.

Zúñiga y Osorio consideran que el Tribunal Constitucional ha ido generando en sus sentencias ciertos criterios que se deben considerar sobre la apertura de la prueba en el procedimiento administrativo sancionador, y que resumen en que:

a) la autoridad no tiene la obligación legal de abrir un término probatorio, salvo que exista en el procedimiento una controversia sobre los hechos $u$ omisiones objeto de investigación; b) la autoridad sancionadora analizará la prueba ofrecida por el inculpado o interesados en el procedimiento y resolverá si esta es pertinente y conducente para el esclarecimiento del caso; c) la autoridad no debe fijar por una resolución los puntos de prueba, en materia administrativa sancionadora hay un derecho para producir todas las pruebas que se estimen conducentes a demostrar la veracidad de las alegaciones, y d) la carga de la prueba corresponde a la autoridad pública en sede administrativa y al infractor o regulado en el contencioso administrativo ${ }^{24}$.

Sin embargo, y sin desconocer la vigencia de los principios de eficiencia, eficacia, celeridad y economía procesal, cuyo objetivo es garantizar la rapidez del procedimiento administrativo y evitar la duplicidad de actuaciones, no es coherente con un racional o justo procedimiento administrativo que la apertura del término probatorio quede entregada a la mera discrecionalidad del órgano administrativo. Por lo tanto, es preciso analizar las limitaciones que dispone la propia ley de procedimiento administrativo, como aquellas que derivan del ordenamiento jurídico administrativo.

\section{a. Hechos relevantes para la decisión del procedimiento administrativo}

Una primera limitación a la discrecionalidad que ostenta la Administración para abrir un término probatorio se relaciona con la existencia de hechos relevantes para la decisión del procedimiento administrativo, lo cual no se encuentra definido por la ley. Sin embargo, acudiendo a la doctrina procesal civil y a las normas comunes a todo procedimiento dispuestas por el libro I del Código de Procedimiento Civil, se entiende que son hechos relevantes aquellos sustanciales, pertinentes y controvertidos.

\footnotetext{
${ }_{23}$ Idem. Orientación propuesta por el Tribunal Constitucional en el considerando $15^{\circ}$ en el sentido que a los procedimientos administrativos sancionadores deben aplicárseles las reglas del procedimiento penal, por ser una manifestación del ius puniendi estatal. Señala también en este sentido, que:

cuestión diversa a lo que ocurre en el procedimiento administrativo sancionador, similar al penal, donde el objeto de la prueba estará constituido por los hechos o enunciados fácticos de la acusación y de la defensa, que en ellos se consideren sustanciales y relevantes.

24 ZÚNIIGa Y OSORIO 2016, 470.
} 
Estimamos que el marco de un procedimiento de elaboración de un acto administrativo, todos los hechos que se ventilen durante la tramitación del procedimiento son relevantes para la elaboración del acto administrativo terminal y para cumplir con el principio de motivación suficiente. En efecto, todos los hechos comprobados por la Administración, mediante distintas potestades, como, por ejemplo, la potestad inspectiva ${ }^{25}$, recogidos en un acta de inspección son relevantes y su omisión puede generar un serio problema de razonabilidad en la motivación del acto administrativo terminal.

A su vez, los hechos que el administrado ventila como hechos relevantes, mediante alegaciones o presentaciones, no pueden ser rechazados en forma categóricamente por la Administración sin que exista una adecuada fundamentación, por cuanto para una correcta apreciación de la realidad sobre la cual la Administración debe ejercer la potestad es preciso analizar conforme a las reglas de la sana crítica la pertinencia y sustancia de estos. Al respecto, la Contraloría General de la República ha señalado que por muy amplia que sea la discrecionalidad otorgada a un órgano de la Administración, ella deberá siempre ejercerla de un modo racional y razonado, lo cual se concreta en materia de prueba en la obligación de emitir una resolución fundada en los casos que la prueba sea calificada como improcedente o innecesaria ${ }^{26}$.

En este sentido, Oelckers señala que, la negativa de la Administración de abrir un período de prueba o a practicar las proposiciones del interesado puede determinar la nulidad del acto terminal en la medida que esa negativa haya producido indefensión. Igual cosa ocurre si la Administración deniega su práctica, si las pruebas son a su criterio innecesarias o inútiles, situaciones que podrán ser calificadas posteriormente para los efectos de la validez o no del acto y su eventualidad ${ }^{27}$.

\section{b. Hechos que no le constan a la Administración}

Una segunda hipótesis en la cual existe obligación de abrir un término probatorio se activa cuando a la Administración no le constan los hechos que surgen durante la tramitación del procedimiento administrativo. Sin embargo, nos debemos preguntar ¿Cuándo no le constan los hechos a la Administración?.

Para responder esta pregunta es necesario efectuar algunas consideraciones relevantes. En primer lugar, no será necesaria la producción íntegra de prueba ni la apertura de un término probatorio cuando se trata de procedimientos administrativos, cuyos antecedentes se encuentra a disposición del órgano administrativo mediante registros públicos que dan cuenta de requisitos para ejercer una actividad o de un estado civil, por ejemplo la solicitud de emisión de un permiso de circulación o un certificado de nacimiento, en ambos casos la documentación se encuentra en poder de la Administración

\footnotetext{
25 VALDIVIA 2018, 276.

26 Dictamen No 39.348 (2007).

27 Oelckers 1999, 279.
} 
y por lo tanto, los hechos le constan. Por el contrario, como señala Letelier, la regla de fundamentación de las decisiones -con todas las garantías que ella concretiza- obliga necesariamente a disponer de prueba que acredite los hechos en que se funda y a valorar dicho material probatorio de una forma determinada ${ }^{28}$.

En segundo lugar, los hechos le constan -al menos en forma parcial- a la Administración, en aquellos casos en que el procedimiento administrativo es consecuencia del ejercicio de la potestad de fiscalización ${ }^{29}$, por cuanto la Administración mediante un funcionario público investido de la calidad de ministro de fe, tiene por objetivo inspeccionar los hechos en los términos más exacto posibles, con el objetivo de motivar la incoación de un eventual procedimiento administrativo sancionador en aspectos tales como, la identificación de las personas que pudieren resultar responsables y las circunstancias relevantes ${ }^{30}$. De esta forma, mediante la inspección administrativa, el órgano público preconstituye prueba que a la postre el legislador le confiere la presunción de legalidad y, en algunos casos una cuestionable presunción de veracidad.

Señalamos que los hechos recogidos por la Administración en un acta de inspección, le consta en forma parcial, por cuanto a pesar del valor probatorio que le asigna el ordenamiento jurídico, el acta de inspección debe ser evaluada conforme a las reglas de la sana crítica, lo que implica que la Administración no puede dar por acreditados los hechos exclusivamente mediante el acta, sino que para dar cumplimiento a un racional y justo procedimiento y respetar el principio de contradictoriedad, es preciso que se fije un término probatorio con el objetivo de producir y ponderar la prueba aportada por el particular interesado.

Siguiendo a Isensee, las tres reglas dispuestas en el artículo 35 de la Ley $N^{\circ} 19.880$, se podrían resumir en la necesidad de probar los hechos relevantes que no le consten a la Administración al momento de revisar y ponderar los elementos fácticos que le sirven de causa al acto administrativo y que constan en la formulación de cargos, concluyendo el autor que el artículo 35 de la Ley $N^{\circ} 19.880$ contiene una regla probatoria que:

regula la distribución de la carga de producir la prueba, debiendo la Administración reunir la evidencia que sustente los cargos comunicados al acusado o formulado de cargos y, por su parte, este debe probar aquellos hechos que avalan la hipótesis o enunciados que propone en sus "descargos"31.

Por lo tanto, solo se admite prueba respecto de aquellos hechos que no le consten a la Administración, que regularmente dirán relación con supues-

\footnotetext{
28 Letelier 2018, 2017. Letelier 2020, 79.

29 Vergara 2020, 150.

30 Cfr. PARejo 2010, 699-700.

31 ISENSEE 2016, 87.
} 
tos de exculpación de los cargos formulados y cuyos antecedentes no hayan sido recopilados durante la etapa de investigación o fiscalización. Lo anterior significa que, para la prueba de exculpación, el administrado se verá en la necesidad de aportar nuevos antecedentes que convenzan al órgano administrativo de la necesidad de abrir un término probatorio, en que además deberán probar las circunstancias exculpatorias de las conductas reprochadas ${ }^{32}$.

Finalmente, consideramos que los hechos no le constan a la Administración y es necesario abrir un término probatorio, en aquellos casos que el procedimiento administrativo se inicia a instancia del particular interesado, sobre todo en aquellos procedimientos en los cuales se discuten materias relevantes, cuya ausencia de un término probatorio puede generar vicios derivados de ausencia de antecedentes, ejemplo autorizaciones administrativas.

\section{c. Naturaleza del procedimiento}

Generalmente se habla que es necesario abrir un término probatorio cuando la naturaleza del procedimiento lo exija, inmediatamente se indica al procedimiento administrativo sancionador, como aquel en el cual es imprescindible la prueba de las infracciones administrativas. La justificación de abrir un término probatorio en el contexto de un procedimiento administrativo sancionador descansa en la exigencia de motivación suficiente y de un racional y justo procedimiento, en atención a que la autoridad administrativa es la encargada de ejecutar todas las actuaciones o diligencias que sean necesarias para esclarecer los hechos u omisiones, ya sea para aplicar una sanción, o para absolver al inculpado ${ }^{33}$.

En efecto, en los procedimientos administrativos sancionadores es imprescindible la apertura de un término probatorio, por cuanto es común que exista controversia sobre hechos o actuaciones recogidas en la formulación de cargos por parte de la Administración, sobre el quantum de la sanción y sobre la existencia y veracidad de los hechos ventilados por el inculpado en sus descargos, así como la invocación de causales de exculpación o de atenuación de la eventual sanción administrativa ${ }^{34}$.

La ausencia de apertura de un término probatorio en el caso de procedimientos sancionadores, tal como lo ha señalado la jurisprudencia ${ }^{35}$, puede generar la nulidad del acto administrativo sancionatorio, por cuanto la apertura

32 Dictamen N ${ }^{\circ} 30.237$ (2016).

33 OsORIo 2017, 840.

34 En relación con estas reglas de pertinencia y necesidad de la prueba, la Corte Suprema ha señalado que "las probanzas ofrecidas por la reclamante fueron consideradas improcedentes desde que la prueba testimonial ofrecida claramente no tenía la aptitud para desvanecer las infracciones a la normativa ambiental sustentadas en estudios científicos emanados de los órganos competentes. (...) Como consecuencia de lo expresado en los motivos anteriores, el ente administrativo legalmente facultado para ello y en mérito de los antecedentes que constaban en el expediente sancionatorio, consideró innecesario otorgar un término probatorio". Sentencia CS, Rol No 9703-2012.

35 Sentencia CS, Rol No 9703-2012. 
de un término probatorio se configura como un requisito esencial, que a la luz del artículo 13 de la Ley $N^{\circ} 19.880$, constituye un vicio de procedimiento no convalidable, por cuanto genera un perjuicio grave y sustancial al inculpado.

\section{d. Término probatorio administrativo y contenciosos especiales}

Finalmente, no obstante, no se encuentra regulado en la ley de procedimientos administrativos una obligación general de conferir un término probatorio específico en todos los procedimientos administrativos, consideramos que una interpretación sistemática del procedimiento administrativo y de los contenciosos administrativos especiales, arrojan como consecuencia la conveniencia de abrir un término probatorio durante la tramitación del procedimiento administrativo, por cuanto los contenciosos administrativos especiales, no regulan instancias de prueba.

En efecto, la vía idónea procesal dispuesta por los contenciosos especiales, bajo la fórmula de recursos de reclamación, generalmente no prevén la oportunidad de abrir un término probatorio. En este caso, se encuentra el artículo $94 \mathrm{~N}^{\circ} 8$, del DL No3.500 que regula la potestad de la Superintendencias de Pensiones de imponer multas, las cuales se pueden reclamar judicialmente ante la Corte de Apelaciones respectiva, sin que exista referencia alguna a la apertura de un término probatorio ante la I. Corte de Apelaciones. La misma hipótesis, se encuentra dispuesta por el artículo 113 del DFL $N^{\circ} 1$, de 2006, del Ministerio de Salud, que contiene la ley orgánica de la superintendencia, que se limita solo a reconocer que la Corte de Apelaciones puede decretar medidas para mejor resolver, sin que exista referencia a abrir un término probatorio.

Consideramos que, en los casos que no existe una instancia de prueba en el contencioso administrativo especial de reclamación, es preciso mantener un adecuado procedimiento racional y justo, en el cual la Administración proceda a abrir un término probatorio durante la tramitación del procedimiento administrativo, con independencia de su naturaleza, por cuanto la ausencia de un período de prueba puede confabular contra el derecho a tutela judicial efectiva, máxime cuando la Administración busca limitar la prueba judicial en los recursos de reclamación solo a hechos nuevos ${ }^{36}$.

De esta forma, ha razonado la Corte Suprema respecto del artículo 171 del Código Sanitario, que obliga al tribunal a desechar la reclamación si los hechos que han motivado la sanción se encuentren comprobados en el sumario sanitario. Al respecto, la Corte Suprema ha señalado que:

(...) como se desprende de la norma transcrita más arriba, al conocer de la reclamación referida los jueces del grado deben, en primer lugar, determinar si los hechos que hayan motivado la sanción se encuentren comprobados, labor en la que han de considerar toda la prueba rendida

36 Arancibia 2016, 162. 
en la causa, tanto la aparejada en sede judicial como aquella agregada en el procedimiento administrativo que precedió a su intervención ${ }^{37}$.

Una propuesta diferente sobre armoización probatoria entre la instancia administrativa y jurisdiccional, es planteada por Letelier, quien señala que, dentro de la impugnación contencioso-administrativo podría justificarse una regla de statu quo que privilegiase la estabilidad y certeza del acto administrativo imponiéndole al actor la obligación de desplegar un esfuerzo probatorio mayor ante el juez que el que tendría la propia administración en el procedimiento para dar por establecidos los hechos constitutivos de la infracción ${ }^{38}$.

Por nuestra parte sostenemos que, cuando los contenciosos especiales de reclamación no prevén la posibilidad de abrir un término probatorio, parece de justicia, que el procedimiento administrativo contemple un período de prueba, porque su ausencia impediría que el particular pueda desacreditar los hechos fijados por la Administración, máxime cuando el control judicial en los mercados regulados -donde el legislador regula recurso de reclamaciónse limita a infracción del principio de proporcionalidad o existe una fuerte deferencia hacía la Administración de Estado ${ }^{39}$.

\section{La carga de la prueba en el procedimiento administrativo}

La doctrina ha identificado el concepto de carga como aquélla que determina:

qué hechos tienen que verificar cada una de las partes en el procedimiento y a quién beneficia la falta de prueba de los mismos. La carga de la prueba formal es la que establece la parte que debe probar. La carga de la prueba material es la que fija la parte que resulta perjudicada por la ausencia de prueba ${ }^{40}$.

Nuestra Corte Suprema, en el "Caso SOM y Seremi de Antofagasta"41, ha señalado que la carga de la prueba "determina sobre quién existe la obligación o el imperativo de acreditar los hechos u omisiones constitutivos de infracción, o las causales de justificación, exculpación o extinción de la responsabilidad administrativa, en un procedimiento administrativo sancionador". De esta manera, en el procedimiento administrativo, la carga de probar los hechos recae en la Administración y el formulado de cargos.

El órgano administrativo deberá probar los hechos que sustentan sus cargos, es decir, "la conducta que configura la infracción y la participación del administrado en ella, mientras que el formulado de cargos deberá hacer lo mismo respecto de sus descargos. Por ello, deberá aportar prueba que se dirija a desvirtuar la acusación, fortaleciendo la presunción de inocencia que

\footnotetext{
37 Sentencia CS Rol No 31870-2017.

38 Letelier 2018, 217.

39 Sentencia CS Rol N²4679-2020. CorvalÁn 2015, 27.

40 Alarcón 2007, 387.

41 Sentencia CS Rol N²267-2015.
} 
lo resguarda, la cual se materializa, entre otras maneras, en su derecho a ser oído previamente" 42 .

En efecto, la necesidad de prueba no puede desvincularse del principio de presunción de inocencia, ya que es a través de la prueba que dicha presunción debe ser desestimada, lo que supone que "solo sobre la base de pruebas cumplidas, cuya aportación es carga de quien acusa (aquí, la propia Administración, en su fase instructora), podrá alguien ser sancionado"43. Por lo tanto, el derecho a la presunción de inocencia hace recaer la carga de la prueba incriminatoria sobre la Administración sancionadora, no existiendo carga del administrado sobre la prueba de inocencia, que aparece directamente presumida por la Constitución. Ahora bien, el hecho de que la presunción de inocencia lo sea "iuris tantum" posibilita naturalmente que la Administración pueda desvirtuar su eficacia mediante la práctica de una actividad probatoria de cargo rodeada de todas las garantías. De este modo, si bien es cierto que la falta de prueba de cargo perjudica a la Administración, no lo es menos que, una vez obtenida esta, la falta de prueba de descargo perjudicará al administrado sujeto al expediente sancionador.

La distribución de la carga de la prueba ha sido reconocida especialmente en procedimientos por infracciones a las regulaciones sanitarias. Así, nuestra Corte Suprema -en materia sanitaria- expresa que "la carga de la prueba de las infracciones sanitarias está sujeta a un sistema diferenciado. En sede administrativa, ella corresponde a la administración"44.

También en el caso "Algorta Norte", reitera esta regla cuando señala que "la norma recién transcrita consagra la reclamación respecto de las sanciones de índole sanitaria estableciendo que la reclamación será desechada si se constata que los hechos fundantes de la acción están comprobados en el respectivo sumario, si los mismos constituyen infracción sanitaria y si la sanción corresponde a la infracción cometida"45.

Sin embargo, la presunción de inocencia se ve afectada dramáticamente con el valor jurídico específico que les asigna el legislador a las actas de inspección. En efecto es frecuente que el legislador les asigne a las actas de inspección una presunción de legalidad, que invierten la carga de la prueba dispuesta por el artículo 1698 del Código Civil, debiendo el particular investigado probar o contradecir lo señalado por el funcionario público, investido de la calidad jurídica de ministro de fe. Ello, se puede apreciar por ejemplo respecto de las actas emitidas por la Superintendencia de Electricidad y Combustible, que en virtud del artículo 3, letra D, de la Ley $N^{\circ} 18.410$, que dispone que los hechos establecidos constituirán una presunción legal; igual

\footnotetext{
42 DroghetTI 2017, 51.

43 García de Enterría 1993, 180.

44 Sentencia CS Rol N²267-2015.

45 Sentencia CS Rol N 7441-2016.
} 
disposición se encuentra regulada en el artículo 11 A, de la Ley N 18.902, de la ley orgánica de la Superintendencia de Servicios Sanitarios.

Recientemente, parte de la doctrina ha entendido que la presunción de legalidad de los actos administrativos debe ser interpretada como una ficción jurídica cuya función o propósito no es más que amparar la realización del interés general y garantizar la eficacia del funcionamiento de la Administración, y no servir de mecanismo para facilitar su prueba en juicio. En efecto, que la presunción de legalidad sea una ficción -en las palabras de Hunter- explica además que la ejecución sea posible una vez que los actos administrativos han quedado firmes, ya sea porque no han sido impugnados o se resolvieron las impugnaciones judiciales o administrativas ${ }^{46}$.

Conjuntamente con la presunción de legalidad de las actas de inspección, el legislador el atribuye una cuestionable presunción de veracidad a los hechos consignados por el funcionario fiscalizador. Ello, implica que los hechos en la forma en que se encuentran consignados en las actas de inspección son ajustados a la realidad, sin que puedan negarse racionalmente su validez.

Ahora si bien, el funcionario fiscalizador puede tener la calidad de ministro de fe, en razón de su carácter técnico y especializado, ello no implica que sus actuaciones revistan la naturaleza de verdad absoluta ni que los hechos ni las declaraciones consignadas en dicho documento estén revestidos de una presunción de derecho, que no admita prueba en contrario, salvo que una norma legal lo diga expresamente ${ }^{47}$.

En la doctrina podemos encontrar dos posiciones doctrinales en torno al valor probatorio de las actas de inspección. La primera que reconoce la legitimidad de la atribución legal de presunción de certeza o veracidad al contenido del acta y que la conecta con la aplicación del principio de eficacia de la Administración, así como a la presunción de validez de los actos administrativos $^{48}$. La otra postura, propugna rechazar el carácter o aplicación de una presunción de veracidad y propone, por el contrario, considerar simplemente que las actas de inspección poseen valor probatorio, y que conforme con las reglas de la sana crítica, será una más de las pruebas que deba valorar conjuntamente el juez ${ }^{49}$.

En cuanto a la naturaleza de esta presunción, la doctrina señala que es iuris tantum o simplemente legal, que no es absoluta ni indiscutible, y por tanto, los hechos e imputaciones consignados en el acta de fiscalización pueden ser enervados por otros medios de prueba, ello como una manifestación de los principios de presunción de inocencia y de un adecuado derecho a la

\footnotetext{
46 HUNTER 2016, 218.

47 Andrade 2012, 16.

48 Rivero 2000, 205-206.

49 Fernández 2002, 474-475.
} 
defensa jurídica que informan los procedimientos administrativos sancionadores ${ }^{50}$. De este modo:

(...) lo verificado por el acta de inspección no posee una verdad absoluta e indiscutible: siempre puede ceder frente a otras pruebas que aportadas por el interesado conduzcan a conclusiones diversas; o bien por objeciones que realicen los propios participantes en el expediente destinadas a desconocer su valor por diversos motivos, que serán apreciados en forma fundada y basados en las reglas de la lógica y las máximas de la experiencia ${ }^{51}$.

En efecto, el acta de fiscalización no tiene valor de prueba absoluta, sino solo de relevancia probatoria, por lo tanto, no obliga al órgano fiscalizador a resolver en el sentido afirmado en ese documento prescindiendo del resultado que arrojen otras pruebas aportadas por el particular durante la tramitación del procedimiento sancionador, siguiendo las reglas de la sana crítica. En este sentido, sin perjuicio del valor jurídico que ostenten las actas de inspección, la carga de la prueba recae sobre la Administración, por cuanto, la presunción de certeza o veracidad del acta de inspección solo alcanza a los hechos directa y objetivamente apreciados por el inspector público. Lo anterior, exige no solo la completa descripción de los hechos, sino también la especificación de la forma como se ha llegado a su conocimiento ${ }^{52}$.

Recientemente, respecto del artículo 166 del Código Sanitario, el Tribunal Constitucional ha señalado que la presencia de un acta de inspección afecta la carga de la prueba y el derecho de defensa y contradictoriedad de un racional y justo procedimiento, por cuanto:

(...) que una tal declaración anticipada de culpabilidad desvirtúa completamente el principio de contradictoriedad, que ha de presidir todo procedimiento administrativo, coarta el derecho de la defensa a tener que discurrir únicamente en torno a esa hipótesis en particular, amén de incentivar -por otro lado- el sesgo confirmatorio del primer atestado efectuado por la autoridad ${ }^{53}$.

Por último, cabe señalar que acta de inspección constituye solo un medio de prueba, dentro del marco de la libertad probatoria en materia administrativa, la cual es apreciada conforme con las reglas de la sana critica, y generalmente, es desacreditada mediante la utilización de informes periciales u otras pruebas técnicas apreciadas conforme con las máximas de la experiencia o los conocimientos científicamente afianzados ${ }^{54}$.

\footnotetext{
50 ROMÁN 2000, 200-202.

51 Jara y Maturana 2009, 15.

52 Cfr., García 2006, 234.

53 Sentencia TC Rol Nº 8823 (2020).

54 RIVERO 2000, 217-218.
} 


\section{Necesidad de fijar los hechos controvertidos en una resolución específica}

Otra materia conflictiva en la prueba dice relación con la fijación de los hechos controvertidos que deberán recibirse a prueba. La Corte Suprema en sentencia dictada en la causa rol 2682 de 2016, ha afirmado que se abrirá un término probatorio cuando exista controversia sobre las circunstancias afirmadas en los cargos ya sea respecto a los hechos, calificación jurídica o la sanción aplicable, pero que no será necesario fijar por una resolución administrativa los puntos de prueba. Indica que la autoridad administrativa en un procedimiento administrativo sancionador no tiene que fijar por resolución los puntos de prueba, ya que en materia administrativa sancionatoria hay un derecho para producir todas las pruebas que se estimen conducentes y pertinentes a demostrar la veracidad de las alegaciones, por cuanto:

una interpretación armónica de esta norma con las antes señaladas, esto es, los artículos 35 de la misma ley y 22 inciso $5^{\circ}$ de la Ley $N^{\circ} 19.913$, lleva a concluir que en el procedimiento administrativo el legislador no contempló la fijación de puntos de prueba, estableciendo el derecho para producir todas las pruebas que se estimen conducentes a demostrar la veracidad de las alegaciones, sin perjuicio del rechazo de las que se estimen improcedentes o innecesarias ${ }^{55}$.

Este análisis es compartido por el Tribunal Constitucional cuando señala que:

no existe principio constitucional ni regla legal que obligue al órgano administrativo persecutor a emitir, en este tipo de investigaciones, un acto interlocutorio donde se fijen los hechos sustanciales y pertinentes que son controvertidos. De suerte que la aplicación del citado artículo 35 no puede configurar una evasión de tal supuesto deber que, por ello, ocasione los efectos inconstitucionales reprochados ${ }^{56}$.

No obstante lo categórico de la jurisprudencia, consideramos que la negativa a la dictación de una resolución específica que recoja los hechos pertinentes, sustanciales y controvertidos, no debe ser analizada desde la óptica estrictamente civil, porque es lógico que el procedimiento administrativo difiere del proceso civil. Sino que es preciso analizar la necesidad de dictar una resolución de prueba, desde la visión garantista del procedimiento administrativo para los ciudadanos. Lo anterior descansa en dos supuestos elementales del debido procedimiento administrativo.

En primer lugar, la visión reduccionista del control jurisdiccional de los actos administrativos mediante reclamaciones de ilegalidad estricta. En este sentido, señala Arancibia que:

\footnotetext{
55 Sentencia CS 23714-2016.

56 Sentencia TC Rol N² 2682 (2014).
} 
Cualquier restricción probatoria en favor de una de las partes configuraría una especie de auto-prueba característica de un régimen de autotutela. En este sentido, la restricción probatoria en el litigio equivale a evidencia por propia mano que anula la tutela judicial efectiva y produce indefensión ${ }^{57}$.

Por lo tanto, ante la restricción de los contenciosos de reclamación de una instancia probatoria general y adecuada, por una parte y la presencia de auto prueba de la Administración, por otra parte, parece razonable y ajustado a un racional y justo procedimiento, que la Administración defina y concretice mediante una resolución fundada cuáles son los hechos que no le constan o si la evidencia recogida en el acta de inspección no es certera ni asertiva, o existen serios defectos y vicios durante la fiscalización que es necesario probar en forma ordenada y coherente.

En segundo lugar, la exigencia de un racional y justo procedimiento no debe quedar entregado a la interpretación exegética, sino que ambos conceptos "racional" y "justo" son extra normativos. En consecuencia, por razones de buena administración, y considerando que la autoridad administrativa goza de prueba preconstituida y, que los tribunales de justicia no son llanos a abrir un término probatorio y se limitan respaldar las decisiones administrativas, es racional y de justicia que en el expediente administrativo exista una resolución que de cuenta de los hechos que deben ser acreditados y luego revisados por los tribunales de justicia.

\section{Libertad en el ofrecimiento de medios de prueba}

La estructura la actividad probatoria regulada en la Ley $N^{\circ} 19.880$, se contiene casi específicamente en el artículo 35, que reconoce la regla general de inclusión de prueba, al señalar los hechos relevantes para la decisión de un procedimiento podrán acreditarse por cualquier medio de prueba admisible en derecho. Junto con ello, el inciso tercero del mismo artículo previene que el instructor del procedimiento solo podrá rechazar las pruebas propuestas por los interesados cuando sean manifiestamente improcedentes o innecesarias, mediante resolución motivada.

En efecto, hay en primer lugar una limitación que se refiere a los medios de prueba admisibles en derecho, que debemos entender como aquellos mecanismos probatorios que autorizados por el ordenamiento jurídico deberán ser considerados en la resolución definitiva como parte esencia de la motivación del acto administrativo. En principio entonces podrá aceptarse todo medio que genere prueba lícita, entendiendo por prueba ilícita:

todo aquel medio probatorio aportado por las partes o por funcionario público, que en sí mismo o en su obtención importe la violación de alguno de los derechos o garantías constitucionales, sin necesidad de existir al respecto sanción procesal expresa ${ }^{58}$.

\footnotetext{
57 ARANCIBIA 2016, 173.

58 Maturana 2012, 290.
} 
Lo anterior es concordante con lo sostenido por Rebollo Puig al señalar que "la presunción de inocencia conlleva la prohibición absoluta de utilizar pruebas ilícitas en los procedimientos sancionadores" y que "la lesión de la presunción de inocencia requiere que la sanción se haya fundamentado exclusivamente en una prueba ilícita", porque las pruebas obtenidas en las que se lesionen los derechos fundamentales del inculpado son incapaces de enervar su presunción de inocencia" ${ }^{59}$, las que se denominan pruebas "excluidas de apreciación" o "valoración prohibida". Además, la sola existencia de prueba ilícita no conlleva a la vulneración del principio de inocencia del inculpado porque si en el procedimiento sancionador se han practicado otras pruebas incriminatorias lícitas e independiente de la obtenida por forma inconstitucional, estas pueden justificar su imposición de la sanción ${ }^{60}$.

Nuestra jurisprudencia agrega la pertinencia del medio probatorio. Al respecto, la Corte Suprema ha señalado ratificando esta atribución legal de la administración cuando señala que "las probanzas ofrecidas por la reclamante fueron consideradas improcedentes desde que la prueba testimonial ofrecida claramente no tenía la aptitud para desvanecer las infracciones a la normativa ambiental sustentadas en estudios científicos emanados de los órganos competentes"61.

Sin perjuicio de lo anterior, considera Navarro que el derecho a aportar pruebas:

resulta fundamental en todo proceso, lo que además es reconocido en la propia legislación administrativa, la que autoriza a que los hechos relevantes para la decisión de todo procedimiento se puedan acreditar por cualquier medio de prueba, estando solo autorizado el instructor para rechazar la misma cuando sea manifiestamente improcedente o innecesaria, lo que se consignará en una resolución motivada (artículo 35 de la Ley $N^{\circ}$ 19.880). Como consecuencia de lo anterior, la autoridad administrativa debe señalar de qué manera -razonando y dando cuenta de los motivos, lo que explicará detalladamente en el expediente administrativo- llegó a la convicción respecto de los hechos, estándole vedado descartar arbitrariamente la prueba ofrecida, bajo sanción de nulidad, lo que además produce la indefensión del imputado ${ }^{62}$.

Agrega Alarcón que las pruebas a rendir serán aquellas:

Que se refieran a cualquier hecho que, de alguna forma, sea tomado en cuenta por el Derecho aplicable en la resolución que haya de dictarse, y ello, a su vez, puede depender de la acusación y la defensa, es decir de

\footnotetext{
59 Corvalán 2016, 9.

60 Rebollo et al. 2009, 629-646.

61 Sentencia CS, Rol N 9703-2012.

62 NaVARro 2014.
} 
los hechos que hayan introducido como fundamento de sus respectivas pretensiones ${ }^{63}$.

Es destacable la libertad probatoria que confiere el artículo 35 de la ley de procedimiento administrativo, al ampliar los medios de prueba más allá de los tasados en los artículos 1698 del Código Civil y el artículo 341 del Código de Procedimiento Civil, lo cual permitiría que los interesados en el procedimiento administrativo puedan presentar mayores alternativa de prueba que el ámbito civil e incluso puedan arbitrar pruebas propias del procedimiento penal o infraccional, tales como grabaciones, documentos electrónicos, fotografías, informes técnicos de partes, entre otros.

La amplitud probatoria tiene directa relación con la obligación de apreciar la prueba en conciencia, esto es, conforme a las reglas de la sana crítica, por cuanto, la apreciación de la prueba conforme a las máximas de la lógica, de la experiencia y los conocimientos científicamente afianzados, obliga a la Administración no solo a apreciar la prueba predatada durante la fiscalización administrativa y asignarle el valor asignado por el legislador, sino que también obliga a la Administración admitir cualquier medio de prueba ajustado a derecho y atribuirle el valor probatorio que en conciencia corresponda, excluyendo las reglas de prueba tasada.

\section{Valoración de la prueba}

\section{a. Sistema de apreciación de la prueba en el procedimiento administrativo}

En lo que respecta a la forma como se valorará la prueba en el procedimiento administrativo, el artículo 35 de la Ley $N^{\circ} 19.880$ dispone que la prueba deberá apreciarse en conciencia ${ }^{64}$, lo que no libera a la Administración de fundar su decisión, puesto que el artículo 11 de la Ley $N^{\circ} 19.880$ la obliga a exponer en forma clara y precisa los hechos y fundamentos de derecho respecto de aquellos actos que limiten, restrinjan, priven, perturben o amenacen el legítimo ejercicio de un derecho o que se pronuncie sobre un recurso administrativo ${ }^{65}$. En efecto, dicha obligación se encuentra ratificada por el texto del artículo 41, cuando dispone que "las resoluciones contendrán la decisión, que será fundada, esto es, motivadas".

Parte de la doctrina ha considerado que la expresión de valorar la prueba "en conciencia" hace en realidad referencia al sistema de la sana crítica, ya que

\footnotetext{
63 Alarcón 2007, 315.

64 Se ha discutido en doctrina si la expresión "en conciencia" que utiliza el legislador puede equipararse a la obligación de valorar la prueba conforme a las reglas de la sana crítica. En este punto existen dos posiciones. Algunos autores consideran que se trataría de un mismo sistema de valoración, ya que ambos se basan en la convicción del juez. Otros consideran que nos encontramos frente a sistemas de valoración distinto, ya que plantea CÁRDENAS 2010, 78, que "la apreciación de la prueba en conciencia a diferencia de la sana crítica el juez actúa conforme a su conocimiento interior del bien que debemos hacer y del mal que debemos evitar, concepto de valor que, aunque constreñido a los antecedentes del proceso, solamente él lo toma en cuenta". 65 LaRroucau 2012, 783-808.
} 
en atención al principio de la discrecionalidad técnica el órgano administrativo está llamado a resolver necesariamente en virtud de las reglas de la lógica, las máximas de la experiencia y los conocimientos científicamente avanzados. Couture ha dicho a este respecto que la "sana crítica" conforma un estándar jurídico cuya proyección abarca a todos los medios de prueba y hacia otros campos de la teoría de la prueba, y que "su valor como tal radica en que consisten en una parte lo suficientemente precisa (las reglas de lógica formal) y en otra lo suficientemente plástica (las máximas o advertencias de la experiencia del juez) como para procurar la justicia de las situaciones particulares"66.

Las Ilamadas máximas de experiencia Couture las define como "normas de valor general, independientes del caso específico, pero como se extraen de la observación de lo que generalmente ocurre en numerosos casos, son susceptibles de aplicación en todos los otros casos de la misma especie" 67. Agrega Alcalá-Zamora y Castillo la sana crítica "debe exteriorizar un juicio razonado que indique, por qué motivos se acepta o rechaza, en todo o en parte, una opinión expuesta, mas sin que oscile de la sumisión ciega a la desconfianza infundada" 68 .

En el mismo sentido, opina Juan Montero Aroca para quien las reglas de la sana crítica son máximas que "no pueden estar codificadas, pero sí han de hacerse constar en la motivación de la sentencia, pues solo así podrá quedar excluida la discrecionalidad y podrá controlarse por los recursos la razonabilidad de la declaración de hechos probados" 69.

La doctrina administrativista, considera que se trata de sistemas distintos en que la diferencia radica en que apreciada la prueba en conciencia:

la Administración deberá expresar los motivos por los cuales adopta tal o cual decisión, sin necesariamente utilizar para ello las reglas de la lógica, las máximas de la experiencia, ni los conocimientos científicamente afianzados, sino únicamente expresar las circunstancias por las cuales resuelve de determinada manera el caso en cuestión, de manera racional y fundada ${ }^{70}$.

La Corte Suprema ratifica este criterio cuando señala que "sistema de apreciación en conciencia, en que se requiere que el medio probatorio produzca certeza en la esfera íntima del juez y este exprese tales circunstancias"71.

Sea cual sea la opción por la cual uno pudiera optar, creemos que la apreciación que realiza el órgano administrativo debe sujetarse a lo que se ha denominado como discrecionalidad técnica, entendida como la "apreciación

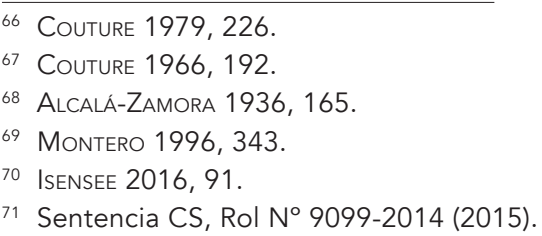


que ha de efectuar la Administración en la aplicación de conceptos jurídicos de carácter técnico ${ }^{72}$, en que la valoración de la prueba debe hacerse estrictamente en base a la realidad fáctica y no a la existencia de otras consideraciones, a fin de otorgar medios de control intersubjetivos de esas decisiones y cuyo acceso a esa verdad (certeza) se ha ajustado a un procedimiento reglado y a pautas y guías lógicas y de experiencia"73.

De esta manera, la valoración de la prueba aportada no es totalmente libre ni discrecional, sino que está rodeada de parámetros que la autoridad administrativa tiene la obligación de cumplir para no caer en la arbitrariedad. Debe efectuar una verificación razonada de la prueba al momento de valorarla debiendo llegar a la verdad a través de los hechos probados en el expediente. Agrega González Pérez que "Si la Administración no hubiese tenido por ciertos los hechos alegados por los interesados y no se hubiese practicado prueba convincente para demostrar la inexactitud de aquéllos, deberá soportar los efectos desfavorables de la falta de la actividad probatoria"74.

Concordamos con González cuando señala que:

el juez llamado a valorar la prueba en conciencia no tiene libertad para valorar; sino que debe atenerse en su labor de sentenciador necesariamente, por lo menos a los dos primeros referentes [máximas de la experiencia y los conocimientos científicamente afianzados]. Si no lo respeta se abre paso a la arbitrariedad judicial y a la incertidumbre de las partes que son las principales objeciones a este sistema de la sana crítica ${ }^{75}$.

En ciertos procedimientos sancionatorios, se ha establecido que el estándar probatorio debería considerar una valoración más allá de una duda razonable, previsto para los procedimientos penales, y que vendría a ser una manera distinta de valorar el material probatorio restringiendo la libertad que implica la valoración en conciencia, favoreciendo al administrado en caso de duda, puesto que en el entender de Taruffo, se aplica cuando "una hipótesis de hecho resulta probada cuando sea más probable que cualquier hipótesis alternativa sobre el mismo hecho manejadas o consideradas en el proceso y siempre que dicha hipótesis resulte "más probable que no"76. En un sentido similar, Letelier señal que la prueba en materia de sanciones administrativas -en tanto técnica de enforcement de prima ratio- debe cumplir de manera general con el estándar de prueba preponderante, es decir, debe ser capaz

\footnotetext{
72 Desdentado 1997, 38-39. No existe en todo caso consenso en este punto. Algunos autores privilegian y prefieren la denominación de "valoración técnica", porque consideran que no deben equipararse los conceptos de discrecional contencioso en el procedimiento administrativo. Vid. en este punto, FERNÁNDEZ 2015, 211-227

73 Morello 1998, 108.

74 GonzÁlez 2004, 323. En sentido similar Diez y Hutchinson 1980, 488, respecto al principio general de apreciación de la prueba: "En caso de duda, debe estarse siempre a favor del administrado".

75 GonZÁleZ 2006, 100.

76 TARUFFO 2008, 138.
} 
de generar una probabilidad simplemente mayor de que los hechos de la infracción ocurrieron ${ }^{77}$.

b. Apreciación comparativa de los medios de prueba y su relación con las actas de inspección en los procedimientos administrativos sancionatorios

Para alcanzar una decisión en el procedimiento, el órgano competente decide según su propia convicción, valorando todas las pruebas en conjunto de modo fundado, ya que el justiciable tiene derecho a obtener de los órganos administrativos "una respuesta razonable, motivada y congruente con las pretensiones oportunamente deducidas por las partes en cualquier clase de procesos" 78 .

La apreciación conjunta de los medios de prueba es consecuencia de la libertad que posee el órgano administrativo en lo que respecta a la valoración de la prueba rendida, ya que primero, procederá a analizar individualmente cada prueba aportada al proceso, y luego lo hará en su conjunto, lo que le permitirá una visión completa de la realidad de los hechos investigados, respecto de los cuales deba ejercer su potestad pública.

Como se ha señalado, un medio de prueba relevante en el procedimiento administrativo chileno se encuentra constituido por el acta de fiscalización, que es un documento emitido por un órgano fiscalizador que recopila el resultado de las actuaciones de comprobación o investigación, declarándose así la conformidad o disconformidad de la actividad inspeccionada en relación con la normativa que la rige ${ }^{79}$.

De esta manera, y siguiendo a Flores:

su exigencia transversal queda reflejada expresamente -en términos precisos- en el artículo 156 del Código Sanitario, el cual dispone que las actuaciones de inspección realizadas por un ministro de fe deben concretarse en un acta de fiscalización. En otros casos el legislador omite el levantamiento de un acta, señalando solo que los hechos constatados por el ministro de fe constituirán presunción de legalidad, como es el caso de la Superintendencia del Medio Ambiente (art. 8 de la Ley $N^{\circ}$ 20.417), la Superintendencia de Electricidad y Combustible (art. 3 $D$, de la Ley $\left.N^{\circ} 18.410\right)$ y la Superintendencia de Servicios Sanitarios (art. $11 \mathrm{~A}$, de la Ley $\left.\mathrm{N}^{0} 18.902\right)^{80}$.

La presunción de veracidad, consecuencia de la presunción de legalidad, permite asumir que los hechos fiscalizados son ciertos, lo que encuentra su justificación en la existencia de una actividad objetiva de comprobación realizada por funcionarios especializados de los órganos de la Administra-

\footnotetext{
77 Letelier 2018, 227. Rodríguez de Santiago 2016, 47.

78 ETO 2011, 294.

79 FERNÁNDEZ 2002, 442.

80 FLORES 2017.
} 
ción, en aras del interés público y con garantías encaminadas a asegurar la necesaria imparcialidad, siendo necesario prueba en contrario para desvirtuar dichas afirmaciones.

Junto con la presunción de veracidad, la doctrina ha entendido que estas actas gozan también de una presunción de legalidad que debe ser interpretada:

como una ficción jurídica cuya función o propósito no es más que amparar la realización del interés general y garantizar la eficacia del funcionamiento de la Administración y la consecuente ejecución del acto administrativo, no el servir de mecanismo para facilitar su prueba en juicio ${ }^{81}$.

En este sentido se pronuncia también Flores, para quien resulta técnicamente incorrecto calificar este tipo de previsiones legales como "presunciones", desde el momento en que no es una norma que se establezca para facilitar la prueba de un hecho a través de la acreditación de otro hecho distinto, sino una regla que pretende atribuir a estos documentos de inspección un determinado valor probatorio.

En ciertas ocasiones, el legislador les atribuye a las actas de inspección expresamente la presunción de veracidad, invirtiendo la carga probatoria. Ello se puede apreciar en las actas emitidas por la SEC, que en virtud del art. 3, letra D, de la Ley $N^{\circ} 18.410$ y el art. 11 A de la Ley $N^{\circ} 18.902$, de la ley orgánica de la Superintendencia de Servicios Sanitarios, disponen que los hechos establecidos constituirán una presunción legal ${ }^{82}$.

Por otro lado, el valor probatorio de las actas elaboradas por los funcionarios alcanza solo a los hechos comprobados por el funcionario, así como a los hechos inmediatamente deducibles de los constatados directamente, así como a los que se acrediten por medio de pruebas que constan en el acta ${ }^{83}$.

Además, coincidimos con Gómez Tomillo cuando señala que las actas y diligencias efectuadas por funcionarios públicos constituyen medios probatorios siempre y cuando versen sobre lo que el funcionario está constatando objetivamente en ejercicio de sus funciones, siendo un primer medio de prueba que excluye toda valoración subjetiva que se pueda realizar sobre lo constatado por cuanto dicha valoración corresponde realizar a la autoridad que instruye y sanciona en el procedimiento ${ }^{84}$.

En definitiva, y como señala Vega, las actas de inspección constituyen:

una prueba documental privilegiada, en tanto se otorga legalmente al contenido de determinados documentos la virtualidad de fundamentar por sí solos una resolución administrativa sancionadora, siempre que

\footnotetext{
81 HUNTER 2016, 218.

82 Cfr. Flores 2017. Vid., Flores, 2014, 279.

83 En este sentido, cfr. Jara y Maturana 2009, 19.

84 Gómez y Sanz 2010, 819.
} 
dicho contenido no sea desvirtuado por otras pruebas de signo contrario cuya proposición y práctica constituyen una carga del presunto responsable ${ }^{85}$.

En consecuencia, considera el mismo autor que los hechos que constatan las actas y diligencias, al igual que los consignados en cualquier otra prueba, "habrán de medirse a la luz del principio de libre valoración de la prueba" 86 ya que constituyen un medio probatorio más entre los distintos medios de prueba que podrán aportarse en un procedimiento de esta naturaleza ${ }^{87}$.

\section{Conclusiones}

1) El debido proceso y el derecho de defensa es una garantía constitucional que encuentra plena consagración en el procedimiento administrativo contemplado en la ley 19.880 y en los procedimientos administrativos particulares, especialmente los de carácter sancionatorio.

2) Por lo anterior, constituye un deber para la Administración el garantizar el derecho a la prueba del interesado, lo que la coloca en la necesidad de abrir un término probatorio aún en procedimientos que no sean de tipo sancionatorio, por cuanto los contenciosos administrativos especiales de reclamación, generalmente, no regulan una instancia probatoria.

3) Dejar la apertura de un término probatorio a la discrecionalidad de la administración podría provocar la indefensión del administrado, especialmente si consideramos que el órgano administrativo goza de prueba preconstituida mediante de las actas de inspección.

4) En lo que respecta a la valoración de la prueba, y sin perjuicio de la expresión "en conciencia" que utiliza el legislador, creemos que dicha apreciación debe ajustarse a un sistema de sana crítica en donde predominen los criterios técnicos, y en donde la apreciación conjunta de los medios de prueba no debe privilegiar las inspecciones o fiscalizaciones que efectúa la administración.

\section{Bibliografía citada}

Accatino, D. (2011). Certezas, dudas y propuestas en torno al estándar de la prueba penal.

Revista de Derecho de la Pontificia Universidad Católica de Valparaíso, (37), 483-511.

AlcalA-Zamora y CAStillo, Niceto (1936). Notas para la reforma de la ley de Enjuiciamiento

Civil Estudios de Derecho Procesal (pp.674-741). Civitas.

\footnotetext{
85 VEGA 1998, 226.

86 Ibíd., 227. Agregan Jara y Maturana, 14 que ello además es posible porque las actas de fiscalización no poseen el carácter de instrumento público, asumiendo los autores que su presunción de validez puede deberse a su carácter de documental.

87 Así puede colegirse del texto del artículo 35 de la Ley $N^{\circ} 19.880$, que establece expresamente que pueden utilizarse todos los medios de prueba admisibles en Derecho. Lo anterior se ve confirmado también por la doctrina. En este sentido, señala GArcía 2006, 229, que las actas son medios de prueba controvertibles que no suponen la inversión de la carga de la prueba.
} 
Alarcón Sotomayor, L. (2007). El Procedimiento Administrativo Sancionador y los Derechos Fundamentales. Thomson Reuters.

Andrade Vergara, M. y Duvauchelle Ruedi, M. (2012). Sumario Sanitario. Precedentes Administrativos. Abeledo Perrot.

Arancibia Mattar, J. Los puntos de prueba en litigios de impugnación de actos administrativos. En: J. Arancibia Mattar y A. Romero Seguel (coord.), La prueba en la litigación pública (pp. 161-190). Librotecnia.

Bermúdez Soto, J. (2011). Derecho Administrativo General (2ª ed.). Thomson Reuters.

Brewer-Carias, A. (2009). Principios generales del procedimiento administrativo: hacia un estándar continental. Procedimiento y justicia administrativa en América Latina (pp. 163-199). Konrad Adenauer Stiftung.

CARDEnAS, M. (2010). La motivación de las sentencias como un elemento de la sana crítica y el recurso de casación en el fondo. Revista de Derecho Consejo de Defensa del Estado, (24), 67-101.

Coloma Correa, R. (2012). ¿Realmente importa la sana crítica? Revista Chilena de Derecho, 39(3), diciembre de 2012, 753-781.

Conget Morral, J. (2015). La prueba como garantía mínima dentro del debido proceso: Análisis jurisprudencial del Tribunal Constitucional. Memoria de prueba, Facultad de Derecho de la Universidad de Chile. http://repositorio.uchile.cl/handle/2250/134942.

Cordero Vega, L. (2015) Lecciones de Derecho Administrativo (2 ${ }^{\mathrm{a}}$ ed.). Thomson Reuters.

Corvalán, J. G. (2015). Estado de Derecho y poderes discrecionales en Estados Unidos de América. Revista de Derecho Administrativo Económico, 20, 5-42.

CorvalÁN, J. G. (2016). Derechos fundamentales, principios jurídicos y discrecionalidad del poder público. Revista de Derecho Administrativo Económico, 22, 5-26.

Couture, E. (1979). Estudios de Derecho Procesal Civil (T. II) (3 ${ }^{a}$ ed.). Depalma.

Couture, E. (1966): Fundamentos del Derecho Procesal Civil. Depalma.

DESDENTADO D. E. (1997). Los problemas del control judicial de la discrecionalidad. Editorial Civitas.

Diez, M. y Hutchinson, T. (1980). Manual de derecho administrativo (T 2). Plus Ultra.

Droghetti Fuentes, P. y Pérez Jiménez, M. J. (2017). La actividad probatoria en el derecho administrativo sancionador a la luz de la ley de bases de los procedimientos administrativos. Universidad de Chile, Memoria para optar al grado de Licenciada en Ciencias Jurídicas y Sociales, Santiago. http://repositorio.uchile.cl/bitstream/ handle/2250/151974/La-actividad-probatoria-en-el-derecho-administrativo-sancionador-a-la-luz-de-la-Ley-de-Bases-de-los-Procedimientos.pdf?sequence=1\&isAllowed=y (Fecha de consulta: 20 de noviembre de 2020).

Eтo CRUz, G. (2011). El desarrollo del Derecho Procesal Constitucional a partir de la jurisprudencia del Tribunal Constitucional peruano. Tribunal Constitucional de Perú.

Fernandez Ramos, S. (2002). La actividad administrativa de inspección. El régimen jurídico general de la función inspectora. Comares.

Fernandez, T. R. (2015). La Discrecionalidad Técnica: Un Viejo Fantasma que se desvanece. Revista de Administración Pública, (196), enero-abril, 211-227.

FIX ZAMUDIO, H. (2005). Concepto y contenido de la justicia administrativa. https://archivos. juridicas.unam.mx/www/bjv/libros/4/1624/9.pdf

FLORES Rivas, J. C. (2017). Actas de inspección y su valor probatorio en el derecho administrativo. https://www.elmercurio.com/legal/movil/detalle.aspx?ld=906120\&Path=/0D/D3/

FLORES Rivas, J. C. (2014). Función fiscalizadora y potestad sancionadora de la Administración del Estado. En J. Arancibia Mattar y P. Alarcón Jaña (Coord.), Sanciones Administrativas $X$ jornadas de Derecho Administrativo (pp. 263-281). Thomson Reuters.

Garcia de Enterría, E. y Fernández, T. R. (1993). Curso de Derecho Administrativo. Editorial Civitas.

Garcia Pino, G. y Contreras Vazquez, P. (2013). El derecho a la tutela judicial y al debido proceso en la jurisprudencia del tribunal constitucional chileno. Revista de Estudios Constitucionales, 11(2), 229-282. 
García Ureta, A. (2006). La potestad inspectora de las Administraciones Públicas. Marcial Pons.

Gómez, M. y SAnz, I. (2010). Derecho administrativo sancionador. Parte general. Teoría y práctica del derecho penal administrativo. Aranzadi.

GonzÁlez Castillo, J. (2006). La fundamentación de las sentencias y la sana crítica. Revista Chilena de Derecho, 33(1), 93-107.

Gonzalez Pérez, J. (2000). Manual de Procedimiento Administrativo. Civitas.

Hunter Ampuero, I. (2016). Es la presunción de legalidad de los actos administrativos una regla de carga de la prueba. En J. Arancibia Mattar y A. Romero Seguel (coord.), La prueba en la litigación pública, (pp. 211-232). Librotecnia.

ISENSEE, Carlos (2016). Debido proceso y su recepción en la Ley NN 19.880: valoración y estándar de prueba en sede administrativa. Revista de Derecho Público, 84(1), 85-97.

Jara Schnettler, J. y Maturana Miquel, C. (2009). Acta de fiscalización y debido procedimiento administrativo. Revista de Derecho Administrativo (3), 1-29.

Larroucau Torres, J. (2012). Hacia un estándar de prueba civil. Revista Chilena de Derecho, 39(3), 783-808.

Letelier Wartenberg, R. (2018). El precio del statu quo. Sobre el estándar probatorio en las sanciones administrativas. Revista de Derecho (Valdivia), 31(1), 209-229.

Letelier WARTEnberg, R. (2020). Sanciones administrativas regulatorias: tres premisas sobre su función. Revista de Derecho Administrativo Económico, 34, 65-83.

Maturana Miquel, C. (2012). Plazos, actuaciones judiciales, notificaciones, resoluciones judiciales y el juicio ordinario conteniendo la teoría general de la prueba. Facultad de Derecho de la Universidad de Chile.

Maturana Miquel, C. (2014). Los principios en el derecho administrativo sancionador y la sanción a la infracción de ellos dentro de un debido proceso en general y su relación particular con un procedimiento seguido por la SVS. http://www.tribunalconstitucional. $\mathrm{cl} / \mathrm{wp} /$ informes-de-derecho.

Montero Aroca, J. (1996). La Prueba en el Proceso Civil. Civitas.

Morello, A. (1998). Estudios de Derecho Procesal. Nuevas demandas, nuevas respuestas. Abeledo-Perrot.

NAVARRo BeltrÁn, E. (2014). El derecho a la prueba en el procedimiento administrativo sancionador. https://www.elmercurio.com/legal/movil/detalle.aspx?ld=903558\&Path=/0D/C9/.

Nieto Garcia, A. (2002). Derecho Administrativo Sancionador. Tecnos.

Oelckers Camus, O. (1999). El derecho a la defensa del interesado en el procedimiento administrativo. Especial referencia al proyecto de ley sobre bases de los procedimientos administrativos. Revista de Derecho de la Universidad Católica de Valparaíso XX, 271-281.

Osorio VARGAS, C. (2017). Manual de procedimiento administrativo sancionador. Parte general $\left(2^{\mathrm{a}}\right.$ ed). Thomson Reuters.

Parejo Alfonso, L. (2010). Lecciones de Derecho Administrativo ( $3^{\mathrm{a}}$ ed.). Tirant lo Blanch.

Poblete ItURRATE, O. (2016). Procedimiento administrativo sancionador y enjuiciamiento posterior de la Administración. En J. Arancibia Mattar y A. Romero Seguel (coord.), La prueba en la litigación pública (pp. 15-83). Librotecnia.

Rivero Ortega, R. (2000). El Estado vigilante. Consideraciones jurídicas sobre la función inspectora de la Administración. Tecnos.

Rodriguez de Santiago, J. M. (2016). Metodología del Derecho Administrativo. Reglas de racionalidad para la adopción y el control de la decisión administrativa. Marcial Pons.

Rojas Franco, E. (2011). El debido procedimiento administrativo. Revista de Derecho PUCP, (67), 177-188.

Rebollo Puig, M., Izquierdo Carrasco, M. L.; Alarcón Sotomayor, L. y Bueno Armijo, A. (2009). Derecho Administrativo Sancionador. Lex Nova.

Román Cordero, C. (2000). El Debido Procedimiento Administrativo Sancionador. Revista de Derecho Público, 71, 183-214.

TARUfFo, M. (2008). La prueba. Artículos y conferencias. Editorial Marcial Pons.

VALDIVIA, J. M. (2018). Manual de Derecho Administrativo. Tirant lo Blanch. 
Vega BorRego, F. (1998). El valor probatorio de las actas y diligencias de la inspección de los tributos en el orden jurisdiccional administrativo y penal. Revista de Estudios Económicos y Empresariales, 11, 223-245.

Vergara Blanco, A. (2011). Esquema del contencioso administrativo: su tendencia hacia un modelo mixto y situación actual del recurso de protección. En J. Arancibia Mattar y Romero Seguel, A. (coord.), Litigación Pública (pp. 37-63). Librotecnia.

Vergara Soto, A. (2020). Fundamentos constitucionales de la potestad fiscalizadora de la Administración del Estado. Revista de Derecho Administrativo Económico, 32, 145-165.

ZúNIIGA URBINA, F. y Osorio VARGAS, C. (2016). Los criterios unificadores de la Corte Suprema en el procedimiento administrativo sancionador. Revista de Estudios Constitucionales, Año 14, (2), 461-478.

\section{Normativa citada}

Ley $N^{\circ} 19.880$ de 2003. Establece bases de los procedimientos administrativos que rigen los actos de los órganos de la Administración del Estado. 29 de mayo de 2003. D.O. $N^{\circ} 37.570$.

Ley N 19.913 de 2003. Crea La Unidad De Análisis Financiero Y Modifica Diversas Disposiciones En Materia De Lavado Y Blanqueo De Activos. 18 de diciembre de 2003. D.O. $N^{\circ} 37.738$.

Ley N 18.092 de 1982. Dicta Nuevas Normas Sobre Letra De Cambio Y Pagare Y Deroga Disposiciones Del Código De Comercio. 14 de enero de 1982. D.O. N 31.165.

Ley N 18.410 de 1985. Crea La Superintendencia De Electricidad y Combustibles. 22 de mayo de 1985. D.O. N ${ }^{\circ} 32.176$.

Ley N²0.417 de 2010. Crea El Ministerio, el Servicio De Evaluación Ambiental y La Superintendencia Del Medio Ambiente. 26 de enero de 2010. D.O. N 39.570.

Decreto $N^{\circ} 1$ de 2005 [con fuerza de ley]. Fija texto refundido, coordinado y sistematizado del decreto Ley $\mathrm{N}^{\circ} 2.763$, de 1979 y de las leyes $\mathrm{N}^{\circ} 18.933$ y $\mathrm{N}^{\circ} 18.469 .23$ de septiembre de 2005. D.O. N 38.446.

Decreto $N^{\circ} 3500$ de 1980. Establece nuevo sistema de pensiones. 13 de noviembre de 1980. D.O. $N^{\circ} 30.814$.

\section{Jurisprudencia citada}

Tribunal Constitucional. Sala. Rol No 1130; 7 de octubre 2008.

Tribunal Constitucional. Sala. Rol No 1448; 7 de septiembre 2010.

Tribunal Constitucional. Sala. Rol No 1411; 7 de septiembre 2010.

Tribunal Constitucional. Sala. Rol No 1838; 7 de julio 2011.

Tribunal Constitucional. Sala. Rol No 1718; 14 de junio 2011.

Tribunal Constitucional. Sala. Rol N² 2682; 13 de agosto 2014.

Tribunal Constitucional. Sala. Rol No 8823; 21 de diciembre 2020.

Contraloría General de la República. Dictamen N 39.348; 30 de agosto 2007.

Contraloría General de la República. Dictamen N 30.237; 22 de abril 2016.

Corte Suprema. Tercera Sala. Rol N 9703-2012; 20 de agosto 2013.

Corte Suprema. Tercera Sala. Rol No 1827-2014; 13 de julio 2015.

Corte Suprema. Tercera Sala. Rol N 2267-2015; 14 de enero 2016.

Corte Suprema. Tercera Sala. Rol No 7441-2016; 19 de abril de 2016.

Corte Suprema. Tercera Sala. Rol N²3714-2016; 26 de abril de 2016.

Corte Suprema. Tercera Sala. Rol No 62128-2016; 9 de mayo 2017.

Corte Suprema. Tercera Sala. Rol No 31870-2017; 18 de agosto 2018.

Corte Suprema. Tercera Sala. Rol N²4679-2020; 10 de diciembre de 2020. 